\title{
The associations of perceived neighborhood disorder and physical activity with obesity among African American adolescents
}

\author{
Akilah Dulin-Keita ${ }^{1 *}$, Herpreet Kaur Thind ${ }^{2 \dagger}$, Olivia Affuso ${ }^{3 \dagger}$ and Monica L Baskin ${ }^{4 \dagger}$
}

\begin{abstract}
Background: According to recent research studies, the built and socioeconomic contexts of neighborhoods are associated with African American adolescents' participation in physical activity and obesity status. However, few research efforts have been devoted to understand how African American adolescents' perceptions of their neighborhood environments may affect physical activity behaviors and obesity status. The objective of the current study was to use a perceived neighborhood disorder conceptual framework to examine whether physical activity mediated the relationship between perceived neighborhood disorder and obesity status among African American adolescents.

Methods: The data were obtained from a cross-sectional study that examined social and cultural barriers and facilitators of physical activity among African American adolescents. The study included a sample of 101 African American adolescents age 12 to 16 years and their parents who were recruited from the Birmingham, Alabama metropolitan area. The primary outcome measure was obesity status which was classified using the International Obesity Task Force cut off points. Moderate-to-vigorous physical activity was assessed via accelerometry. Perceived neighborhood disorder was assessed using the Perceived Neighborhood Disorder Scale. Mediation models were used to examine whether the relationship between neighborhood disorder and obesity status was mediated by physical activity.
\end{abstract}

Results: Perceived neighborhood disorder was significantly and positively related to obesity status and moderate-to -vigorous physical activity was inversely associated with obesity status. However, there was no evidence to support a significant mediating effect of moderate-to-vigorous physical activity on the relationship between neighborhood disorder and obesity status.

Conclusion: Future studies should longitudinally assess perceived neighborhood disorder characteristics and childhood adiposity to examine the timing, extent, and the mechanisms by which perceived neighborhood disorder characteristics increase the risk of obesity.

Keywords: Neighborhood, Physical activity, Obesity, Adolescent, Race/ethnicity

\footnotetext{
* Correspondence: akilah_keita@brown.edu

${ }^{\dagger}$ Equal contributors

${ }^{1}$ Institute for Community Health Promotion, Department of Behavioral and

Social Sciences, Brown University, Providence, RI, USA

Full list of author information is available at the end of the article
} 


\section{Background}

Participation in physical activity is a key health promoting behavior that prevents weight gain and reduces the risk for obesity $[1,2]$. However, there are age-related declines in physical activity levels among adolescents with peak declines evidenced between 15 to 18 years of age [3-6]. While both national and international guidelines suggest that adolescents engage in a minimum of $60 \mathrm{mi}-$ nutes of moderate-to-vigorous physical activity daily, less than 10 percent of all US adolescents age 12 to 15 years meet this recommendation $[2,5,7]$. When the physical activity estimates are examined across racial/ethnic groups, the research findings suggest that African American adolescents are unlikely to meet the recommendations for moderate-to-vigorous physical activity [7] and African American adolescents in this age group are more likely to be overweight or obese relative to other racial/ethnic groups [5]. Data from the National Health and Nutrition Examination Survey (NHANES 2009-2010) indicate that 41.2 percent of African American adolescents age 12 to 19 years are either overweight or obese (23.7 percent are obese) relative to 30.0 percent of white adolescents age 12 to 19 years (16.1 percent are obese) [8]. These research findings indicate that African American adolescents' declines in physical activity levels are consistent with national declines among US adolescents, but also indicate that African American adolescents encounter higher levels of obesity.

Features of the neighborhood environment may contribute to the declines in physical activity and the higher levels of obesity among African Americans. Relative to other racial/ethnic groups, African American adolescents are more likely to reside in low-income urban areas that have more built environment barriers such as poor housing stock, sidewalks, street design and greater traffic density within neighborhoods [9,10]. African American adolescents also live in neighborhoods with higher levels of social, physical and economic disorder which include features such as lack of trust among neighbors, abandoned buildings, crime, graffiti and concentrated poverty that contribute to social instability [10-13]. While research findings indicate that built environment features associated with physical activity such as less availability of parks, poor neighborhood walkability and street connectivity are associated with low levels of physical activity [14-17], the associations of the built environment with obesity are less clear. Support for the association of the built environment with adolescent obesity is inconsistent with a significant association found among some, [1,18-20] but not all research $[21,22]$. Additional research that examines the social contexts of the neighborhood suggests that low socioeconomic status may contribute to low levels of physical activity $[23,24]$. However, the associations of neighborhood socioeconomic status with obesity are inconclusive; some studies indicate that neighborhood level socioeconomic status is inversely associated with obesity [24-28], whereas others do not find significant associations $[29,30]$.

While the literature on the roles of the neighborhood built and economic environments provide compelling evidence to develop further insights into neighborhood level effects on physical activity and obesity, the subjective contexts of African American adolescents' neighborhood perceptions and the relationships with physical activity participation and obesity status, are less researched. Although social factors such as neighborhood safety, social cohesion, and perceptions of crime have been examined among multi-ethnic cohorts of adolescents participating in research studies such as the Healthy Passages Study [31], additional neighborhood features that might specifically affect African American adolescents' participation in physical activity and obesity outcomes warrant attention.

The purpose of the current study was to examine the relationships of perceived neighborhood physical and social disorder with physical activity and obesity status among African American adolescents. To examine this objective, we utilized the conceptual framework developed by Burdette and Hill [32], which suggests that perceived neighborhood disorder is indirectly related to obesity through a series of mediating factors. According to the model outlined by Burdette and Hill [32], observable indicators of neighborhood social and physical disorder such as crime, public loitering, vandalism, graffiti, and abandoned buildings, are associated with psychological and physiological distress. These indicators of neighborhood disorder may induce psychological distress because of heightened perceptions of potential risks to physical safety and/or victimization. Individuals who experience psychological distress may not engage in regular physical activity and are potentially more likely to engage in obesogenic sedentary behaviors and have poorer diet quality (e.g. greater fat and sugar intakes). Additionally, the increase in psychological distress may result in chronic activation of the physiological stress response and may lead to negative coping such as poorer diet quality and less participation in physical activity. While the conceptual framework outlines psychological and physiological distress as pathways to obesity, the current study did not include measures of physiological or psychological distress. However, the perceived neighborhood disorder conceptual framework is applicable to the current study aims as there are additional pathways through which neighborhood disorder may contribute to obesity. The research findings of Evenson et al. [33] suggest that disordered neighborhood environments may directly discourage physical activity within neighborhoods due to fear of crime and/or the absence of physical activity promoting resources. Therefore we hypothesized that 
among African American adolescents, the association between perceived neighborhood disorder and obesity would be mediated by physical activity.

\section{Methods}

Data for the current study are from a cross-sectional study that examined the social and cultural factors that influence African American adolescents' participation in physical activity.

\section{Subjects}

To meet eligibility criteria for the study, adolescents had to be 12 to 16 years of age, self-identify as African American and present with no physical or mental impairment. Adolescents and their parents were recruited from the Birmingham, Alabama metropolitan area, where the population is predominantly African American (73.4 percent) and where 32.7 percent of families with children have incomes below the poverty level (US Census Bureau: American FactFinder. Available at http://factfinder2.census.gov/faces/nav/jsf/pages/community_facts.xhtml). To recruit study participants, we used passive recruitment methods, where participants identified themselves as potential participants, and active recruitment methods, where our research team identified and targeted potential participants [34]. The passive recruitment strategies included posted flyers (with the contact information of the project coordinator provided on the flyer) at local recreational centers, churches, community centers, newspaper advertisements posted on the University website, and word-of-mouth advertising by previous study participants. Active recruitment for this study included staff initiated phone contacts with adolescents who participated in the phase 1 qualitative portion of this study and targeted recruitment of adolescents from one afterschool program at a community center. For this study, passive recruitment via word-of -mouth was the most effective recruitment strategy. All study materials, methods, and study ethics were approved by the Institutional Review Board of the University of Alabama at Birmingham.

To identify an acceptable sample size for this study, we generated a series of multivariate linear regression models using the PASS statistical software. The sample size was calculated based on a significance level $\alpha=0.05$ with varying levels for beta such that Power (1- Beta) equals $0.90,0.85$, or 0.80 . The sample size calculations were adjusted for the multivariate nature of the analyses by including a conservative estimate of the $R^{2}\left(R^{2}=\right.$ $0.10)$ that is attained when family income, a primary independent variable used in our proposed sampling procedure, is regressed on 10 other independent variables in the regression models. The sample size calculations are strong evidence that the proposed sample size of 120 provided enough power to conduct the multivariate analysis for this study.

Data were collected in Spring 2011 and all study related events were held at the University of Alabama at Birmingham, Division of Preventive Medicine. Of the 145 adolescents screened to be eligible, 116 (54 percent female and 46 percent male) completed the study. The remaining 29 eligible participants reported scheduling conflicts as the main reason for not participating in the study meetings.

\section{Procedures}

Parents and adolescents who expressed interest in the study were invited to participate in a 90-minute study meeting. Prior to study participation, trained staff obtained informed consent from the parents and assent from the adolescents. During the meeting, adolescents and their parents completed self-administered paper surveys and the adolescents received accelerometers, which they returned approximately one week after the initial meeting. Parents and adolescents received $\$ 10$ each for completing the surveys and adolescents received an additional \$25 dollars for wearing and returning the accelerometer.

\section{Measurements \\ Dependent variables}

Body mass index (BMI) Trained research staff collected anthropometric measurements. To obtain height measurements, adolescents' were measured without shoes using a portable stadiometer (Seca 213). Height was measured to the nearest $0.1 \mathrm{~cm}$. To obtain weight measurements, adolescents wore light clothing and were weighed without shoes to the nearest $0.1 \mathrm{~kg}$ using a digital scale (Seca 813). Two independent measurements were taken for weight and the average of the two was used. BMI was calculated using the formula $\mathrm{kg} / \mathrm{m}^{2}$.

Obesity status BMI was collapsed into categories of normal weight, overweight or obese using the International Obesity Taskforce cut offs which average data from six countries (Brazil, Great Britain, Hong Kong, Netherlands, Singapore and the United States) [35]. The age-sex specific centile curves correspond to adult cut off points of $25 \mathrm{~kg} / \mathrm{m}^{2}$ (overweight) and $30 \mathrm{~kg} / \mathrm{m}^{2}$ (obese) at age 18 years of age.

\section{Independent variables}

Perceived neighborhood disorder Parents and adolescents self-reported neighborhood conditions using the full 15-item version of the Ross and Mirowsky Neighborhood Disorder Scale [36]. Because there were no 
significant differences in mean neighborhood disorder scores between parents and adolescents, we used adolescent responses for all analyses. The Neighborhood Disorder statements assessed perceptions of physical and social disorder and a prosocial neighborhood environment. Examples of the scale items include 'there are too many people hanging around on the streets near my home,' 'my neighborhood is noisy', and 'I can trust most people in my neighborhood.' A Likert format ('strongly agree $=4$ to 'strongly disagree' $=1$ ) was used to collect response options for the neighborhood disorder scale. For this scale, the prosocial neighborhood environment items were reverse coded. The responses for the items were summed and the possible score values were 15 to 60 , with higher scores indicating greater perceived neighborhood disorder. The Cronbach's alpha was $\alpha=$ 0.913 . We constructed quartiles to examine outcomes of interest by quartiles of perceived neighborhood disorder.

\section{Physical activity \\ Objective assessment}

We assessed adolescents' physical activity via accelerometry. Adolescents wore the Actigraph uniaxial accelerometers (Model GT1M; Actigraph Manufacturing Technology Inc., Pensacola, FL, USA) which have demonstrated high reliability for this population [37]. The research staff explained the purpose of the accelerometer and demonstrated its use at the study meeting. Adolescents were asked to wear the accelerometers at their waist for 7 consecutive days including nights and were instructed to remove them only for bathing or swimming purposes. To improve compliance with the accelerometer protocol, at least two reminders were sent through email, text message, or phone call based on the participants' desired method of contact. We followed the protocols of Toriano et al. [7] for collecting accelerometer data. Epoch length was set at one minute and data were expressed as counts per minute (counts $\mathrm{min}^{-1}$ ). Accelerometry data were considered valid if counts were present for at least three days with at least 8 hours of recording per day. We used validated child and age specific algorithms to determine physical activity [7]. We converted the accelerometer data to Metabolic Equivalents (METs). Daily and total counts per minute were summed and averaged as minutes spent in sedentary (1 to $1.5 \mathrm{METs}$ ), light (1.5 to 4 METs), moderate (4 to $7 \mathrm{METs}$ ) and vigorous (> $7 \mathrm{METs}$ ) physical activity. We used these criteria for METs to account for the higher resting energy expenditure of adolescents [38]. Because children engaged in few minutes of vigorous physical activity, values were combined with moderate physical activity.

\section{Subjective assessment}

Adolescents recorded their daily physical activity for two weekdays and one weekend day using the validated
3-Day Physical Activity Recall log (PDPAR) $[39,40]$. Each log was divided into 30 minute blocks and the adolescents recorded their main activity for each block. Adolescents provided open-ended responses, which were used to identify types of physical activity that adolescents engaged in while wearing accelerometers. Trained staff coded the open-ended responses to the 71 activities included in the 3DPAR logs using established methodology [39]. The staff then calculated the average time spent on each activity.

\section{Covariates}

Age, sex, and socioeconomic status were examined as possible covariates. Parents reported for the child the age and sex of the child. Age was examined as a continuous measure and sex was examined as a categorical variable. To obtain measurements of socioeconomic status, parents self-reported their total annual household income and the highest level of education completed by any adult in the household ( 1 = less than high school, $2=$ complete high school, $3=$ some college, and $4=$ college graduate). For analyses, income and education were treated as ordinal variables.

\section{Data analysis}

All variables were examined for normality using the Shapiro-Wilk test. Because there were some variables that were not normally distributed, we conducted nonparametric statistical tests where appropriate. Initially, we conducted analyses stratified by gender but found no significant differences; thus, all analyses presented include results for both girls and boys together. Means, standard deviations, and percentages were computed for the dependent and independent variables by quartiles of perceived neighborhood disorder. Simple bivariate correlations for all independent variables were evaluated to test for multicollinearity $[41,42]$. None of the variables were significantly correlated and all independent variables and covariates were included for analysis. One-way ANOVA, Kruskal-Wallis tests or Chi-square were conducted to assess significant differences for the dependent and independent variables $\alpha<.05$, by quartiles of perceived neighborhood disorder.

We conducted single mediation analyses to examine whether the relationship between neighborhood disorder and body mass index was significantly mediated by physical activity. In these analyses, we assessed neighborhood disorder as a continuous variable and examined adolescent obesity status categories $(1=$ normal weight, $2=$ overweight and 3 = obese) that corresponded to the International Obesity Taskforce centile curves. To examine the indirect (mediational) effect in these models, we used the bootstrap procedures outlined by Preacher and Hayes [43] and we used their publicly available Indirect 
SAS macros available at http://www.afhayes.com/spsssas-and-mplus-macros-and-code.html. Bootstrapping is a nonparametric procedure that is robust to departures from the assumptions of normally distributed sampling distributions and is the most appropriate method for small sample sizes [43]. We included the bias-corrected $(\mathrm{BC})$ and bias-corrected and accelerated $(\mathrm{BCa})$ confidence intervals to account for the asymmetric distribution of point estimates [43]. We set the BCa confidence intervals at 0.95 with 5000 resamples for bootstrapping [43]. To model the quadratic association of education with obesity, we created a variable, squared-education for each participant and this non-linear effect was added as a covariate along with education in the mediation models. As recommended by Preacher and Hayes, all of the point estimates presented in the mediation analysis are the unstandardized beta coefficients [43]. The probability criterion was set at $\alpha<0.05$. We used SAS version 9.2 (SAS Institute Inc, Cary, NC) for all analyses.

\section{Results \\ Descriptives}

Of the 116 adolescents who participated in the study, 15 were excluded due to missing/incomplete data (nine were missing information on perceived neighborhood disorder, four were missing information on income, one was missing information on BMI and one did not have accelerometer data for three days). There were no significant differences between adolescents with missing data and participants included in data analyses in age, sex, socioeconomic status, perceived neighborhood disorder, moderate-to-vigorous physical activity, or BMI, so no imputation was applied.

Table 1 presents means of the full perceived neighborhood disorder scale, as well as physical disorder, social disorder and prosocial environment subscales for the full sample. On average, the participants averaged in the middle-range of values of perceived neighborhood disorder and the various subscales.

Table 2 presents the characteristics of the participants for the full sample and by quartile of neighborhood disorder, where higher quartiles indicate greater perceived

Table 1 Descriptives of the perceived neighborhood disorder scale and subscales

\begin{tabular}{lc}
\hline & Full sample ( $\mathbf{N}=\mathbf{1 0 1})$ \\
\hline${ }^{ \pm}$Neighborhood disorder (15 - 60) & $26.81 \pm 8.96$ \\
Physical disorder subscale $(4-16)$ & $6.67 \pm 2.91$ \\
Social disorder subscale $(6-24)$ & $8.29 \pm 3.55$ \\
${ }^{*}$ Prosocial environment subscale (20-5) & $11.86 \pm 4.40$ \\
\hline
\end{tabular}

${ }^{ \pm}$Neighborhood disorder and subscales, values in parentheses represent range of possible values.

*Prosocial environment is reverse coded, with lower scores representing a more prosocial environment. neighborhood disorder. There were no significant differences in the age or sex of participants by quartile of disorder. A significantly greater percentage of overweight and obese children were in the highest quartile of perceived neighborhood disorder. There were no significant differences in total minutes spent in physical activity at any activity level by quartile of perceived neighborhood disorder. There were also no significant differences in self-reported minutes spent participating in physical activities (i.e. basketball, football, dance, walking) by quartile of perceived neighborhood disorder. There were no significant differences in income by quartile of perceived neighborhood disorder. There were also no significant differences in education levels by perceived neighborhood disorder; and almost half of the adolescents in the sample resided in households where an adult had obtained a college degree or higher.

\section{Mediation model}

Figure 1, Panel a presents the unstandardized beta coefficients for the unmediated association of perceived neighborhood disorder with obesity status, while controlling for income, education, age and sex. Perceived neighborhood disorder was significant and positively related to obesity status. Panel b of Figure 1 presents the unstandardized beta coefficients for the model examining whether moderate-to-vigorous physical activity mediated the relationship of perceived neighborhood disorder on obesity status. Perceived neighborhood disorder was not significantly related to moderate-tovigorous physical activity. However, moderate-to-vigorous physical activity was significant and inversely associated with obesity status. The direct path of perceived neighborhood disorder remained statistically significant and there was no evidence that moderate-to-vigorous physical activity mediated the relationship of perceived neighborhood disorder on obesity status (Table 3 ). We also examined whether vigorous physical activity mediated the associations of perceived neighborhood disorder on obesity status (data not shown) and found results similar to those presented.

\section{Discussion}

This study set out to examine if subjective reports of perceived neighborhood disorder were associated with objectively measured physical activity and obesity status among African American adolescents. For the current study, accelerometer data indicated that the adolescents were engaged in low levels of moderate-to-vigorous physical activity (less than 30 minutes daily) and almost half of the adolescents (43 percent) were either overweight or obese. Using the conceptual model developed by Burdette and Hill [32], it was hypothesized that living in disordered neighborhoods would affect obesity status 
Table 2 Demographic characteristics, body mass index and physical activity by quartile of perceived disorder, higher quartiles indicate higher perceived disorder

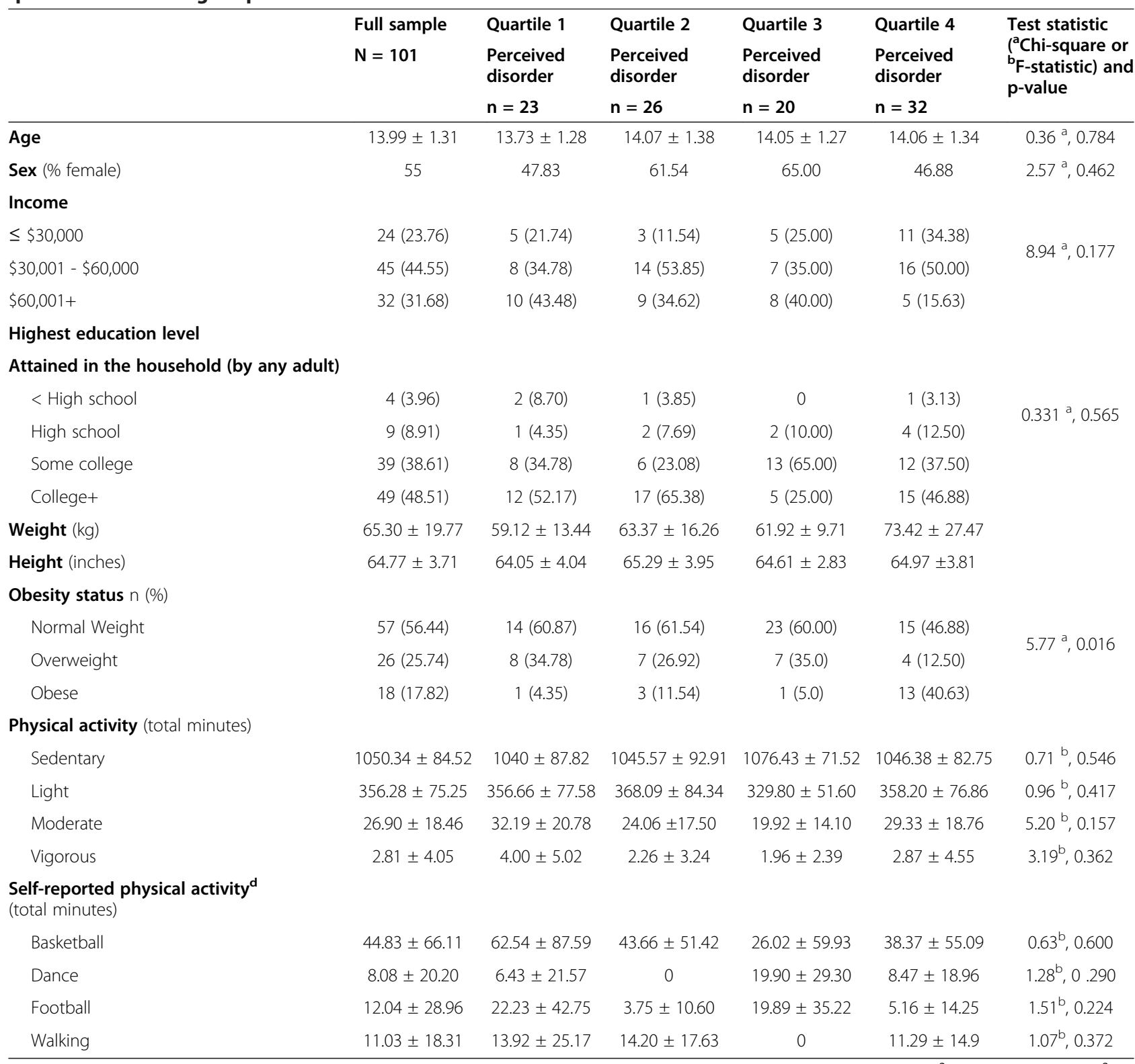

Obesity Status categories were developed using the International Obesity Taskforce estimates that correspond to overweight $\left(25 \mathrm{~kg} / \mathrm{m}^{2}\right)$ and obesity $\left(30 \mathrm{~kg} / \mathrm{m}^{2}\right)$ at 18 years of age.

$\mathrm{a}, \mathrm{b}$ refer to the test statistic used to test for significant differences between quartiles.

${ }^{\mathrm{d}}$ Self-reported physical activity logs were completed by the adolescents, the data reported represent the average minutes spent in the most frequently reported activities for boys and girls.

through less participation in physical activity. The current research provides partial support for the conceptual model and suggests that while adolescents' perceptions of neighborhood disorder are significantly related to obesity status, physical activity may not be a significant mediator of this relationship.

The current study findings are supported by the literature evaluating relationships of neighborhood social context on obesity. Evenson and colleagues assessed the relationship between neighborhood factors and BMI for adolescent girls and their findings suggest that neighborhood factors such as low levels of crime, seeing other children playing outside, and the availability of recreational facilities are associated with lower BMI [33]. Although they note that the influence of neighborhood factors is minimal, the neighborhood context may be important and may operate to protect adolescent girls from obesity [33]. In the current study, the associations are also minimal, but statistically significant. While some research studies do not find significant associations of 


\section{$0.025 p=0.004$}

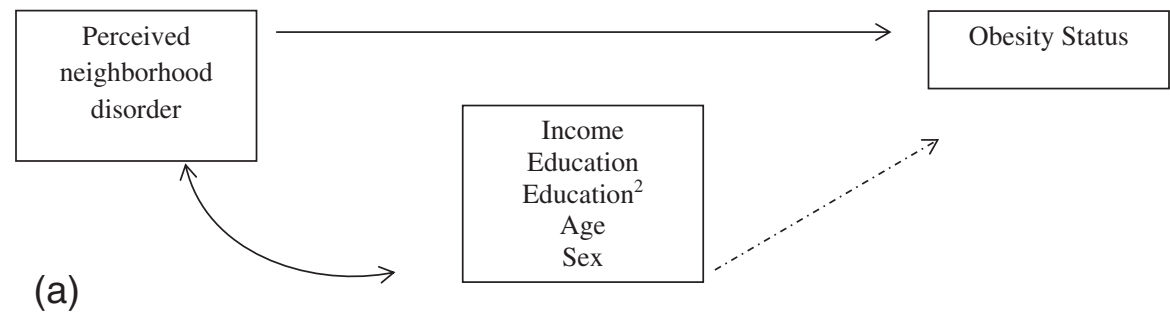

(b)
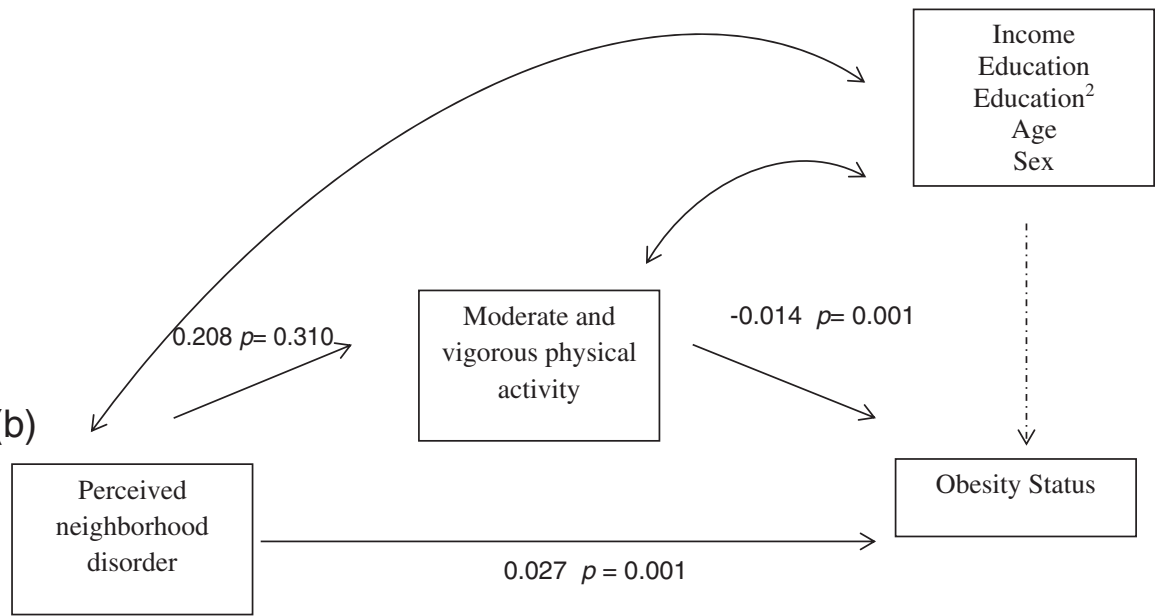

Figure 1 Simple mediation model for the relationships between perceived neighborhood disorder and obesity status. Panel (a) path estimates for the direct effect of perceived neighborhood disorder on obesity status (controlling for income, education, education ${ }^{2}$-to control for the non-linear effects of education, age and sex) (b) path estimates of the indirect effect of perceived neighborhood disorder on obesity status (controlling for income, education, education ${ }^{2}$-to control for the non-linear effects of education, age and sex).

neighborhood context with obesity among children $[29,44]$, the associations observed during adolescence may suggest that the obesogenic effects of neighborhood disorder emerge over time. For the current study, adolescents who live in disordered neighborhoods are more obese and because obesity tracks into adulthood, they may have increased risks for adverse health outcomes later in life. Future studies should longitudinally assess perceived neighborhood disorder characteristics and childhood adiposity to examine the timing and extent to which perceived neighborhood disorder characteristics begin to develop into increased obesity risk among youth.

Contrary to the expected findings outlined by the conceptual model, we did not find significant associations between perceived neighborhood disorder and objectively measured physical activity. While a few studies report significant associations between neighborhood disorder and physical activity, these studies typically rely upon self-reported physical activity assessments [32,45-47]. However, the use of accelerometry in the current study provides an objective measurement of physical activity and contributes to the literature that suggests a null relationship. Previous studies using objectively measured physical activity also indicate that neighborhood safety and disorder may not be associated with child and adolescent physical activity levels [48]. Studies that examine area-level SES also do not find significant relationships with physical activity [24]. $\mathrm{Cu}$ mulatively, these research findings may suggest that neighborhood social contexts are not associated with physical activity when physical activity is measured objectively.

Table 3 Indirect effects of perceived neighborhood disorder on obesity status among adolescents (unstandardized)

\begin{tabular}{|c|c|c|c|c|}
\hline \multirow[b]{2}{*}{ Model summary for Obesity Status } & \multirow[t]{2}{*}{ Bias-corrected point estimate $(a b)$} & \multirow[t]{2}{*}{ S.E. } & \multicolumn{2}{|c|}{$\begin{array}{l}\text { Bias-corrected accelerated bootstrap } \\
95 \% \text { confidence interval }\end{array}$} \\
\hline & & & Lower & Upper \\
\hline Moderate \& vigorous physical activity & 0.000 & 0.003 & -0.010 & 0.004 \\
\hline
\end{tabular}


However, there may be specific neighborhood features of social and physical disorder that directly affect physical activity. When we examined bivariate correlations between individual items from the perceived neighborhood disorder scale and physical activity (data not shown), specific elements of neighborhood disorder such as drug use in the neighborhood, was significantly and negatively associated with participation in moderateto-vigorous physical activity among adolescents. Evenson and colleagues also examined specific social and built environment factors related to physical activity and showed that while perceived neighborhood crime is not associated with physical activity, factors such as street lights, recreational facility access, and the presence of other children playing outside are associated with greater non-school related physical activity participation for adolescent girls [33]. Therefore, while perceived neighborhood social disorder such as crime levels may decrease feelings of safety, it appears that population density on the streets may provide a buffering effect [33]. Future studies that incorporate accelerometry should separate school based physical activity from nonschool based physical activity and disaggregate features of neighborhood disorder to determine the extent to which neighborhood factors may affect physical activity among children. This type of research is especially important if children get most of their physical activity at school [26].

The current study findings provide support for the inverse association of moderate-to-vigorous physical activity with obesity status. Although most children in this study did not meet daily recommendations of at least 60 minutes of moderate-to-vigorous physical activity, their participation in physical activity appeared to be protective against obesity. We also examined other types of physical activity data from the accelerometers including models of participation in light or vigorous physical activity in association with obesity, but found no significant associations (data not shown). As a supplement to the objective accelerometer data, we also examined adolescents' qualitative reports of the types of physical activities that they participated in and the duration of these activities. Among adolescent girls, the most frequently reported physical activities were walking for exercise, dance, and basketball. Among boys, the most frequently reported activities were basketball, football and walking for exercise. Although adolescents subjectively reported being physically active, the accelerometer data reflected that the activity levels were insufficient to meet the recommended physical activity guidelines. However, research findings from a nationally representative sample of children and adolescents, indicate that children and adolescents are more likely to engage in unstructured sporadic physical activity than structured physical activity [49]. These sporadic bouts of physical activity are inversely associated with overweight and obesity and are independent of total physical activity. This suggests it is important to measure both sporadic physical activity in addition to a measure of moderate-to-vigorous physical activity [49].

Because physical activity did not appear to mediate the association of perceived neighborhood disorder and obesity, future research should analyze the additional neighborhood disorder pathway of diet, which is a key component of the perceived neighborhood disorder conceptual model outlined by Burdette and Hill [32]. Fast food density and grocery store access, and fruit and vegetable availability are known to differ by neighborhood context [50-55] and these neighborhood features are associated with poorer diet quality and adolescent obesity [56,57]. An exploration of the relationship to diet in conjunction with the neighborhood pathway through physical activity may provide more evidence for the mechanisms through which perceived neighborhood disorder affects adolescent obesity.

While informative, this study is not without limitation. The sample size is relatively small and was obtained from a limited geographical region. As such, the current findings may not be generalizable to African American adolescents as a whole. Further, the sample data are cross-sectional in nature and therefore causality could not be established. Also, while the use of accelerometer data strengthened the findings, the data presented may not represent regular physical activity patterns of adolescents throughout the year. Additionally, research suggests that since children engage in very short bouts of sporadic vigorous physical activity, the 60 second epoch length of the accelerometery may underestimate the amount of moderate-to-vigorous physical activity patterns of the adolescents [58]. Further, this study did not include subjective or objective measures of stress as suggested by the conceptual model of Burdette and Hill [32]. Future work should incorporate these measures to examine the extent to which neighborhood disorder directly affects psychological and physiologic functioning.

Despite the study limitations, this research has significant strengths and contributes to the neighborhood and health literature by incorporating a conceptual model to examine the mechanisms through which perceived neighborhood disorder may affect obesity risk among African American adolescents, a population who experiences higher prevalence of obesity. Further, the inclusion of traditional measures of body mass index coupled with objective measures to assess physical activity, strengthen the current study findings and suggest that perceived neighborhood disorder and the low levels of physical activity observed among adolescents may contribute to obesity. Future intervention efforts to reduce obesity 
among African American adolescents should be developed to address strategies to increase physical activity and to modify features of the perceived neighborhood environment contexts that are directly associated with obesity.

\section{Conclusions}

The current study findings highlight the associations of adolescents' perceptions of neighborhood disorder and physical activity with obesity status among African American adolescents, a population who is at high risk for both low-physical activity participation and obesity. While the findings indicate that physical activity may not mediate associations of neighborhood disorder on body mass, both may play a role in contributing to obesity. Therefore, community-based interventions to decrease obesity among African American adolescents should devote attention to both neighborhood perceptions and physical activity outcomes.

\section{Competing interests}

The authors declare that they have no competing interests.

\section{Authors' contributions}

AJK, HT and MLB were involved in the conception and design. AJK conducted the analysis. AJK and HT wrote the first version. OA was involved with interpretation of the physical activity data. All of the authors were involved with drafting and revising the article and final approval.

\section{Acknowledgements}

This study was funded by Active Living Research (ALR)/Robert Wood Johnson Foundation (RWJF) Grant \# 65659 (MLB). The manuscript development was also supported by Award Number P30DK056336 from the National Institute Of Diabetes And Digestive And Kidney Diseases and T32DK062710, R00-DK83333. The content is solely the responsibility of the authors and does not necessarily represent the official views of the Robert Wood Johnson Foundation, the National Institute Of Diabetes And Digestive And Kidney Diseases or the National Institutes of Health.

\section{Author details}

${ }^{1}$ Institute for Community Health Promotion, Department of Behavioral and Social Sciences, Brown University, Providence, RI, USA. ${ }^{2}$ Centers for Behavioral and Preventive Medicine, Department of Psychiatry \& Human Behavior, Brown Alpert Medical School and the Miriam Hospital, Providence, RI, USA. ${ }^{3}$ Department of Epidemiology, University of Alabama at Birmingham, Birmingham, AL, USA. ${ }^{4}$ Division of Preventive Medicine, University of Alabama at Birmingham, Birmingham, AL, USA.

\section{Received: 18 September 2012 Accepted: 25 April 2013}

Published: 4 May 2013

\section{References}

1. Norman GJ, Adams MA, Kerr J, Ryan S, Frank LD, Roesch SC: A latent profile analysis of neighborhood recreation environments in relation to adolescent physical activity, sedentary time, and obesity. J Publ Health Manag Pract: JPHMP 2010, 16(5):411-419.

2. Rogers HL, Bhattaram A, Zineh I, Gobburu J, Mathis M, Laughren TP, Pacanowski M: Cyp2d6 genotype information to guide pimozide treatment in adult and pediatric patients: basis for the US Food and Drug Administration's new dosing recommendations. J Clin Psychiatry 2012, 73(9):1187-1190.

3. Dovey SM, Reeder Al, Chalmers DJ: Continuity and change in sporting and leisure time physical activities during adolescence. Br J Sports Med 1998, 32(1):53-57.

4. Kimm SY, Glynn NW, Kriska AM, Fitzgerald SL, Aaron DJ, Similo SL, McMahon RP, Barton BA: Longitudinal changes in physical activity in a biracial cohort during adolescence. Med Sci Sports Exerc 2000, 32(8):1445-1454.
5. Lawman HG, Wilson DK, Van Horn ML, Resnicow K, Kitzman-Ulrich H: The relationship between psychosocial correlates and physical activity in underserved adolescent boys and girls in the ACT trial. J Phys Act Health 2011, 8(2):253-261.

6. Sallis JF: Age-related decline in physical activity: a synthesis of human and animal studies. Med Sci Sports Exerc 2000, 32(9):1598-1600.

7. Troiano RP, Berrigan D, Dodd KW, Masse LC, Tilert T, McDowell M: Physical activity in the United States measured by accelerometer. Med Sci Sports Exerc 2008, 40(1):181-188.

8. Ogden $\mathrm{CL}$, Carroll MD, Kit BK, Flegal KM: Prevalence of obesity and trends in body mass index among US children and adolescents, 1999-2010. JAMA 2012, 307(5):483-490.

9. Handy SL, Boarnet MG, Ewing R, Killingsworth RE: How the built environment affects physical activity: views from urban planning. Am J Prev Med 2002, 23(2 Suppl):64-73.

10. Franzini L, Taylor W, Elliott MN, Cuccaro P, Tortolero SR, Janice Gilliland M, Grunbaum J, Schuster MA: Neighborhood characteristics favorable to outdoor physical activity: disparities by socioeconomic and racial/ethnic composition. Health Place 2010, 16(2):267-274.

11. Areas with concentrated poverty:1999. http://www.census.gov/prod/ 2005pubs/censr-16.pdf.

12. Where we live matters for our health: Neighborhoods and health. http://www. commissiononhealth.org/PDF/888f4a18-eb90-45be-a2f8-159e84a55a4c/Issue \%20Brief\%203\%20Sept\%2008\%20-\%20Neighborhoods\%20and\%20Health. pdf.

13. Galvez MP, Hong L, Choi E, Liao L, Godbold J, Brenner B: Childhood obesity and neighborhood food-store availability in an inner-city community. Acad Pediatr 2009, 9(5):339-343.

14. Boone-Heinonen J, Popkin BM, Song Y, Gordon-Larsen P: What neighborhood area captures built environment features related to adolescent physical activity? Health Place 2010, 16(6):1280-1286.

15. Nelson MC, Gordon-Larsen P, Song Y, Popkin BM: Built and social environments associations with adolescent overweight and activity. Am J Prev Med 2006, 31(2):109-117.

16. Norman G, Sutter SK, Ryan S, Sallis JF, Calfas K, Patrick K: Community design and access to recreational facilities as correlates of adolescent physical activity and body-mass index. Physical Activity and Health 2006, 3 (Supplement 1):S118-S128.

17. Pate RR, Colabianchi N, Porter D, Almeida MJ, Lobelo F, Dowda M: Physical activity and neighborhood resources in high school girls. Am J Prev Med 2008, 34(5):413-419.

18. Gordon-Larsen P, Nelson MC, Page P, Popkin BM: Inequality in the built environment underlies key health disparities in physical activity and obesity. Pediatrics 2006, 117(2):417-424.

19. Slater SJ, Ewing R, Powell LM, Chaloupka FJ, Johnston LD, O'Malley PM: The association between community physical activity settings and youth physical activity, obesity, and body mass index. I Adolesc Health: official publication of the Society for Adolescent Medicine 2010, 47(5):496-503.

20. Wolch J, Jerrett M, Reynolds K, McConnell R, Chang R, Dahmann N, Brady K, Gilliland F, Su JG, Berhane K: Childhood obesity and proximity to urban parks and recreational resources: a longitudinal cohort study. Health Place 2011, 17(1):207-214.

21. Kligerman M, Sallis JF, Ryan S, Frank LD, Nader PR: Association of neighborhood design and recreation environment variables with physical activity and body mass index in adolescents. Am J Health Promot: AJHP 2007, 21(4):274-277.

22. Ewing $R$, Brownson $R C$, Berrigan D: Relationship between urban sprawl and weight of United States youth. Am J Prev Med 2006, 31(6):464-474.

23. Shishehbor MH, Gordon-Larsen P, Kiefe Cl, Litaker D: Association of neighborhood socioeconomic status with physical fitness in healthy young adults: the Coronary Artery Risk Development in Young Adults (CARDIA) study. Am Heart J 2008, 155(4):699-705.

24. Voorhees CC, Catellier DJ, Ashwood JS, Cohen DA, Rung A, Lytle L, Conway TL, Dowda M: Neighborhood socioeconomic status and non school physical activity and body mass index in adolescent girls. J Phys Act Health 2009, 6(6):731-740.

25. Chen E, Paterson LQ: Neighborhood, family, and subjective socioeconomic status: How do they relate to adolescent health? Health Psychol: official journal of the Division of Health Psychology, American Psychological Association 2006, 25(6):704-714. 
26. Franzini L, Elliott MN, Cuccaro P, Schuster M, Gilliland MJ, Grunbaum JA, Franklin F, Tortolero SR: Influences of physical and social neighborhood environments on children's physical activity and obesity. Am J Public Health 2009, 99(2):271-278.

27. Lumeng JC, Appugliese D, Cabral HJ, Bradley RH, Zuckerman B: Neighborhood safety and overweight status in children. Arch Pediatr Adolesc Med 2006, 160(1):25-31

28. Veugelers $P$, Sithole F, Zhang S, Muhajarine N: Neighborhood characteristics in relation to diet, physical activity and overweight of Canadian children. Int J Pediatr Obes: IJPO: an official journal of the International Association for the Study of Obesity 2008, 3(3):152-159.

29. Burdette HL, Whitaker RC: Neighborhood playgrounds, fast food restaurants, and crime: relationships to overweight in low-income preschool children. Prev Med 2004, 38(1):57-63.

30. Whitaker RC, Orzol SM: Obesity among US urban preschool children: relationships to race, ethnicity, and socioeconomic status. Arch Pediatr Adolesc Med 2006, 160(6):578-584.

31. Molnar BE, Gortmaker SL, Bull FC, Buka SL: Unsafe to play? Neighborhood disorder and lack of safety predict reduced physical activity among urban children and adolescents. Am J Health Promot: AJHP 2004, 18(5):378-386

32. Burdette AM, Hill TD: An examination of processes linking perceived neighborhood disorder and obesity. Soc Sci Med 2008, 67(1):38-46.

33. Evenson KR, Scott MM, Cohen DA, Voorhees CC: Girls' perception of neighborhood factors on physical activity, sedentary behavior, and BMI. Obesity (Silver Spring) 2007, 15(2):430-445.

34. Raynor HA, Osterholt KM, Hart CN, Jelalian E, Vivier P, Wing RR: Evaluation of active and passive recruitment methods used in randomized controlled trials targeting pediatric obesity. Int J Pediatr Obes: IJPO : an official journal of the International Association for the Study of Obesity 2009, 4(4):224-232.

35. Cole TJ, Bellizzi MC, Flegal KM, Dietz WH: Establishing a standard definition for child overweight and obesity worldwide: international survey. BMJ 2000, 320(7244):1240-1243.

36. Ross CE, Mirowsky J: Disorder and decay - The concept and measurement of perceived neighborhood disorder. Urban Aff Rev 1999, 34(3):412-432.

37. Evenson KR, Catellier DJ, Gill K, Ondrak KS, McMurray RG: Calibration of two objective measures of physical activity for children. J Sports Sci 2008, 26(14):1557-1565.

38. Trost SG, Pate RR, Sallis JF, Freedson PS, Taylor WC, Dowda M, Sirard J: Age and gender differences in objectively measured physical activity in youth. Med Sci Sports Exerc 2002, 34(2):350-355.

39. Pate RR, Ross R, Dowda M, Trost SG, Sirard JR: Validation of a 3-day physical activity recall instrument in female youth. Pediatr Exerc Sci 2003, 15(3):257-265

40. Weston AT, Petosa R, Pate RR: Validation of an instrument for measurement of physical activity in youth. Med Sci Sports Exerc 1997 29(1):138-143

41. Wheeler D, Tiefelsdorf M: Multicollinearity and correlation among local regression coefficients in geographically weight regression. J Geographic Systems 2005, 7:161-187.

42. Zwaan RA, Graesser AC, Magliano JP: Dimensions of situation model construction in narrative comprehension. J Exp Psychol Learn 1995, 21(2): 386-397.

43. Preacher KJ, Hayes AF: Asymptotic and resampling strategies for assessing and comparing indirect effects in multiple mediator models. Behav Res Methods 2008, 40(3):879-891.

44. Whitaker D, Milam AJ, Graham CM, Cooley-Strickland M, Belcher HM, FurrHolden CD: Neighborhood Environment and Urban Schoolchildren's Risk for Being Overweight. AJHP: American journal of health promotion; 2013.

45. Carver A, Salmon J, Campbell K, Baur L, Garnett S, Crawford D: How do perceptions of local neighborhood relate to adolescents' walking and cycling? Am J Health Promot: AJHP 2005, 20(2):139-147.

46. Gomez JE, Johnson BA, Selva M, Sallis JF: Violent crime and outdoor physical activity among inner-city youth. Prev Med 2004, 39(5):876-881.

47. Heinrich KM, Lee RE, Suminski RR, Regan GR, Reese-Smith JY, Howard HH, Haddock CK, Poston WS, Ahluwalia JS: Associations between the built environment and physical activity in public housing residents. Int J Behav Nutr Phys Act 2007, 4:56.
48. Adkins S, Sherwood NE, Story M, Davis M: Physical activity among AfricanAmerican girls: the role of parents and the home environment. Obes Res 2004, 12(Suppl):38S-45S.

49. Mark $A E$, Janssen I: Influence of bouts of physical activity on overweight in youth. Am J Prev Med 2009, 36(5):416-421.

50. Block JP, Scribner RA, DeSalvo KB: Fast food, race/ethnicity, and income: a geographic analysis. Am J Prev Med 2004, 27(3):211-217.

51. Moore LV, Diez Roux AV: Associations of neighborhood characteristics with the location and type of food stores. Am J Public Health 2006, 96(2):325-331.

52. Powell LM, Slater S, Mirtcheva D, Bao Y, Chaloupka FJ: Food store availability and neighborhood characteristics in the United States. Prev Med 2007, 44(3):189-195.

53. Richardson AS, Boone-Heinonen J, Popkin BM, Gordon-Larsen P: Are neighbourhood food resources distributed inequitably by income and race in the USA? Epidemiological findings across the urban spectrum. BMJ open 2012, 2(2):e000698.

54. Keita AD, Casazza K, Thomas O, Fernandez JR: Neighborhood-level disadvantage is associated with reduced dietary quality in children. J Am Diet Assoc 2009, 109(9):1612-1616.

55. Keita AD, Casazza K, Thomas O, Fernandez JR: Neighborhood perceptions affect dietary behaviors and diet quality. J Nutr Educ Behav 2011, 43(4): 244-250.

56. Larson NI, Story MT, Nelson MC: Neighborhood environments: disparities in access to healthy foods in the U.S. Am J Prev Med 2009, 36(1):74-81.

57. Rahman T, Cushing RA, Jackson RJ: Contributions of built environment to childhood obesity. Mt Sinai J Med, New York 2011, 78(1):49-57.

58. Nilsson A, Ekelund U, Yngve A, Sjostrom M: Assessing physical activity among children with accelerometers using different time sampling intervals and placements. Pediatr Exerc Sci 2002, 14(1):87-96.

\section{doi:10.1186/1471-2458-13-440}

Cite this article as: Dulin-Keita et al:: The associations of perceived neighborhood disorder and physical activity with obesity among African American adolescents. BMC Public Health 2013 13:440.

\section{Submit your next manuscript to BioMed Central and take full advantage of:}

- Convenient online submission

- Thorough peer review

- No space constraints or color figure charges

- Immediate publication on acceptance

- Inclusion in PubMed, CAS, Scopus and Google Scholar

- Research which is freely available for redistribution 